Article

\title{
Smart, Digitally Enhanced Learning Ecosystems: Bottlenecks to Sustainability in Georgia
}

\author{
Eka Jeladze * and Kai Pata \\ School of Digital Technologies, Tallinn University, 10120 Tallinn, Estonia; kpata@tlu.ee \\ * Correspondence: ekajel@tlu.ee; Tel.: +372-5351-1982
}

Received: 1 June 2018; Accepted: 27 July 2018; Published: 30 July 2018

\begin{abstract}
This paper stems from the need to identify the sustainability bottlenecks in schools' digital transformation. We developed the conceptual model of the smart, digitally enhanced learning ecosystem to map transformation processes. We posit that the notion of sustainability is central to conceptualize learning ecosystems' smartness. The paper presents the mapping results of Georgian public schools' data using the interviews from 62 schoolteachers, ICT managers, and school principles. The qualitative content analysis revealed that even the schools with comparative digital maturity level could not be considered as smart learning ecosystems that are transforming sustainably. The findings call for the design of technology integration in the school as a dynamic transformation that balances two sustainability intentions-to stabilize the current learning ecosystem with its present needs, while not compromising its pursuit to test out possible future states and development towards them. We suggest schools build on the inclusion of different stakeholders in digital transformation; nourishing their resilience to ruptured situations; widening the development, testing, and uptake of digitally enhanced learning activities; weaving internal networks for sharing new practices; conducting outreach to change the socio-technical landscape; and developing feedback loops from learning, data, and information flows to manage the changes.
\end{abstract}

Keywords: school transformation; sustainability; smart ecosystem; digitally enhanced learning environment; change management

\section{Introduction}

Technology is considered a powerful driver of educational change and innovation [1-3] while bringing new requirements to schools [4]. Digital innovation is an accelerator of cultural change because it prompts wider adaptation of new uncertain and precarious conditions of contemporary living [5]. It entails the shift in education to provide learners with new knowledge and skills [6]. There have been repeated calls to restructure the schools to take advantage of technologies $[4,7]$. Though, effective integration is still missing in the school context $[3,8]$. Its use and related methodologies have a slow growth, and increased availability has not been associated with better learning outcomes in schools, while it has been the major driver of productivity in other public sectors [9]. In the dynamically changing and technology-enriched environment, important questions are how schools operate efficiently within the new requirements, what the bottlenecks that impede digital transformations are, or whether the digital innovations are sustainable there.

Effective integration of technology into the educational system recognizes that technology will transform the learning environment [4]. Transformation does not happen by a linear chain of causal steps, rather this is shaped by a set of complex interacting influences $[4,10]$. The importance of system-level synergy, rather than success of independent factors, is highlighted in different strategic review documents [11-13], organizational learning theories [14,15], as well as current thinking on educational changes [16]. 
The study of digital learning requires understanding of the context. Technology does not cause direct change; rather, it facilitates or amplifies the educational practices. The environment into which it is placed may or may not be supportive for beneficial technology integration [16]. We have the constant flux in the environment where the digital learning is situated. The rapidly evolving nature of the technologies causes disturbances to the educational system, challenges the structures and rules of an educational environment, and constantly redefine available opportunities [4]. These new realities require flexibility, openness to change, and responsiveness to the potential opportunities from the organizations [17].

Teaching and learning do not take place in the closed systems and behavior needs the time to be evolved in response to the changing environments [7]. Taking into account the rapidly evolving technology and dynamically changing environment we posit, that schools' functioning on an organizational level as well as their relation to the external environment are important variables to study schools' digital transformation. Several theories embrace a system-wide approach to study how organizations learn in a fast changing environment. Systems thinking theory claims to understand the forces and interrelationships that shape system behavior. The theory highlights the use of mental models to control the system behavior by means of reinforcing and balancing feedback loops [14]. However, it emphasizes the whole rather than dynamically evolving structure of the system. Double Loop Learning model [15] focuses on inward behavior and explains the need for self-organized learning through critical reflection, identification of possible contributions to the organization, and changing the behavior accordingly. The model promotes the environment of inquiry and experiments in the organization. In this paper we build on system thinking and double-loop learning theories. We use the concepts of feedback loop and self-organization that we will further explain in the following chapter. However, we conceptualize the school as dynamically evolving living ecosystem that is constantly shaped by and in relation to the external environment [18]. We try to go a step further and explore not only the school-level system where the digital learning is situated, but also its interaction and interdependence with the external environment it is embedded into.

We use the conceptual model of a smart, digitally enhanced learning ecosystem to describe the schools and their dynamic interaction with the environment, as well as inside the organization. Ecosystem metaphor has been intensely referred to as an analytical framework to describe dynamics of interaction of the actors and elements with each other and with the whole system $[7,19]$. The ecological perspective in this article provides a rationale for the behavior of complex and adaptive school system, as well as its interaction and interdependence to the external environment where it is embedded, and informs about its sustainable functioning [7]. Our conceptual model of Smart, Digitally Enhanced Learning Ecosystem defines ecosystem's current state-sustaining as a well-functioning ecosystem - and its responsiveness to future adaptive states [20]. In our understanding, the smartness of learning ecosystem is defined through sustainability. We posit that interactions between internal, as well as across internal, components of learning ecosystem and the external socio-technical landscape can indicate the sustainability - the potential of the schools to sustain the digital changes and being efficient at their current level of digital maturity, and being adaptively responsive to the future states. Solutions are sustainable when they address the promotion of the individuals' well-being and they are doing it by offering opportunities for growth and enrichment [21]. Sustainability—as the development state that meets the present needs without compromising the future-may be seen as a static as well as a dynamic notion of the systems.

The purpose of this paper is to develop the concept of smart, digitally enhanced learning environment and analyze the bottlenecks of its sustainability using the Georgian schools example. We will answer the research questions: What characterizes smartness of digitally enhanced learning ecosystems? What supports schools to advance and sustain smartness in the context of surrounding socio-technical landscape? What are the deterrents that impede the schools to sustain smartness in digitally enhanced learning environment? We believe that the study of school-level digital innovation-by placing it in the scope of external environment-can be a useful finding for the 
community, mainly in understanding schools' sustainability in terms of changing environment, and the reasons of low and high responsiveness. It can also allow relevant stakeholder communities to participate in the discussions and enhance school alignment to the wider external environment. In the following chapters we will define the concept of smart, digitally enhanced learning ecosystems. We will provide the background on Georgia, where the study took place, and present the bottlenecks of sustaining digitally enhanced learning ecosystems in the sample of digitally more advanced schools. In the discussion we will introduce our suggestions for prompting the smartness and sustainability of the digitally enhanced learning ecosystems.

\section{Smart, Digitally Enhanced Learning Ecosystems}

This section provides the conceptual model of the smart, digitally enhanced learning ecosystem.

We define smart, digitally enhanced learning ecosystems as ecosystems that dynamically evolve through participatory governance of human agents, and which have the ability to sense and adapt to the changing external environment for the good of the ecosystem members. Smartness is a functional measurable quality of learning ecosystem that is related to its sustainability in the current state and its potential to be responsive to the future states.

Using the ecosystem metaphor we refer to two criteria to measure the smartness of the ecosystem: (a) Responsiveness of the ecosystem to the changes in external environment and also to its human agent needs; (b) effectiveness of the ecosystem in the current succession level. First, we will define the digitally enhanced learning ecosystem, as we understand it. Then we will proceed with the description of the criteria of smartness for digitally enhanced learning environments. Finally, we summarize how these criteria contribute to sustainability of learning ecosystems.

\subsection{Underpinning Assumptions}

1. School as a learning ecosystem comprises of the connected living (humans) and nonliving (infrastructure) species, as well as digital and other types of services (teaching and learning processes, rules, etc.) where species participate. Ecologists have recognized that one or more species often have a major influence on the form of a stable ecosystem. Zhao \& Frank [19] used the term 'Keystone species' and suggested that ICT may supplant the teacher as the keystone species in schools. However, [7] recognizes that teachers are the keystone species and technology as an environmental change stimulates the changes in their behavior. Teachers are identified as bearers of the major effect in education and the most important variable for successful system-wide change [12,22,23].

The theory of the organism-environment system [24] proposes that in any functional sense, organism and environment are inseparable and form one unitary system. According to [24], mental activity is not something located in the organism, but extends into the environment. The environment itself is not something passively surrounding the organism, but an active part of the cognitive system leading to the results of behavior. Albrechtsen et al. [25] also refer to the mutuality between actor and environment as the constituent basis for the actor's perception and action.

Hence, the primary unit of analysis is neither the actor nor the environment as distinct categories, but the total ecosystem of actors and environment. We observe the teachers' behaviors in the ecosystem and the technology as an environmental factor that changes their exposed behavior and educational ecosystem. The rationale of our thinking follows this cycle: New requirements, artifacts, and tools rupture the learning ecosystem. Teachers, as the major mediators of change, notice the signals and begin changing their behavior to match the ruptured situation. The ecosystem begins actuating itself (processes, tools, etc.) to meet the requirements. We will discuss this cycle more thoroughly below.

2. Maturity models and tools that share systems approach describe the schools in terms of infrastructure, resources and tools, learning instruction and assessment, leadership, professional development, and support [4,11,26-29]. We follow the existing experience of systemic approach of maturity models and furthermore state that all these components are human-developed, and humans need to perceive and use them to make the ecosystem function. In our conceptual model, we group 
these elements and represent them in three ecosystem components: Mediating assets, transforming assets, and flows. Digital infrastructure, tools, and resources represent mediating assets that are necessary to host the flows that permeate through the ecosystem. Transforming assets are the transformational services that enable, restrict, or empower the interaction between all the assets such as incentives or support systems, rules and guidelines, facilitation and training, and change management activities necessary to transform the ecosystem. Both mediating and transforming components contribute to creating the digital learning, information, and data flows [20]. The main goal of the learning ecosystem is to permeate "knowledge transformation" flows through the ecosystem. Learning and teaching is conceptualized as the energy that fuels learning ecosystems and transforms the "information" into different kinds of "knowledge" [30,31].

3. School as the digitally enhanced learning ecosystem is embedded in the wider ecosystem-the socio-technical landscape of the country and the world [32]. The relation between the school ecosystem and socio-technical landscape is two-way in nature. Learning ecosystem functioning adapts to the external landscape, but the assets in the ecosystem also transform the external landscape to make it fit. The changed landscape transforms the learning ecosystem back in a continuous circle. People together transform their world and are transformed by it in a continuous flow of transformative action [18].

\subsection{Responsiveness of Smart, Digitally Enhanced Learning Ecosystems}

Smart, digitally enhanced learning ecosystems respond to the individual and collective needs of all its assets, as well as to the dynamically changing internal and external environment. Responsiveness describes the different agents' interaction between internal and external environments. First, we refer to the response and adaptation to the external environment as the socially constructed capacity of the organization. Responsiveness is the ability of an organization to respond to the environment by mitigating negative threats or capitalizing on positive opportunities generated by the environment [33]. It is socially constructed attribute of an organization and refers to the perceptual, reflective, and adaptive dimension of an organization [34]. Second, responsiveness entails organization's capacity to change underlying processes to recognize and interpret those changes in external environment [35].

For our understanding, learning ecosystem's responsiveness entails its sensing, actuating, and self-organizing abilities (Figure 1).

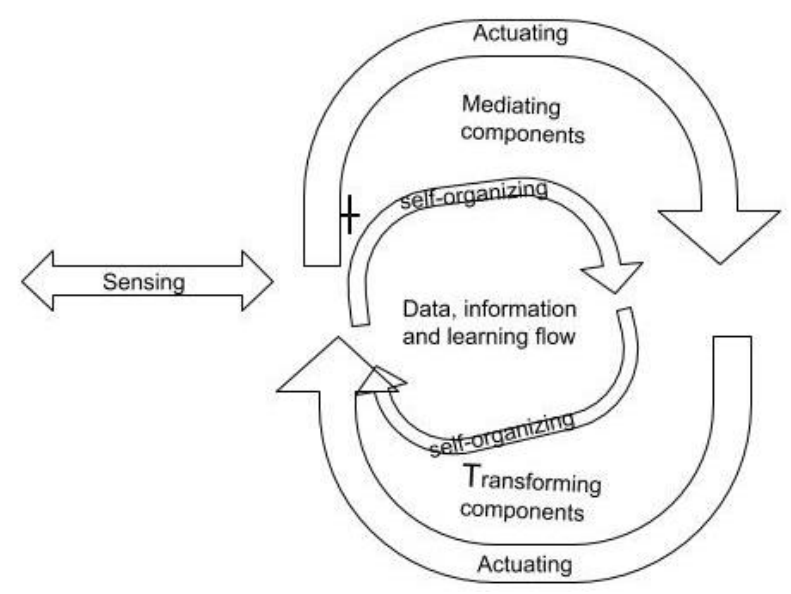

Figure 1. Smart, digitally enhanced learning environment. The "+" symbol indicates the self-reinforcement processes in the ecosystem through actuating and self-organization processes.

Sensing describes how the ecosystem assets can send and receive signals among themselves and with the socio-technical landscape, creating the feedback loops. Examples of sensing in digitally enhanced schools are: (i) Direct communication and awareness building means about external/internal requirements and appearing digital innovation opportunities; (ii) indirect communication and 
awareness building means, e.g., if an ecosystem's accumulated assets are shared digitally, they may convey the signals of good digital learning approaches, resources may be ranked up by the users if they are digitally shared and this accumulated signal may be used to change learning in schools. In ecology, the feedback loop concept is used to describe how the change in one part or asset of the ecosystem impacts other parts or assets in the ecosystem, and then feeds back the source of the change. In a positive feedback loop, one asset or part of the system causes an increase to the system in such a way that it brings self-reinforcement to the system [14]. Self-reinforcement causes instability to the ecosystem. It is the force of change that drives the system outside of its normal parameters and eventually contributes to its future orientedness.

Ecosystem is able to self-reinforce the processes, to use the sensing data to make predictions, and be future-oriented. In the smart, digitally enhanced learning ecosystem we would expect the ecosystem to sense the changes in the technology-enriched socio-technical landscape, and reinforce the system with feedback loops. The learning ecosystem adapts itself to meet opportunities and requirements. For example, schools recognize the importance to develop the digital skills of the students, as the labor market requires it. Applying a Bring Your Own Device (BYOD) environment in schools is the response to the opportunity that owning smart devices has created for ubiquitous learning. Changes in the usage of digital tools in schools will reinforce the changes in digital infrastructure, as well as practicing new digitally enhanced pedagogical approaches and establishing digital flows and feedback loops, such as learning analytics about digital competences. Learning analytics reinforces the active change management to accommodate the system to be efficient.

Actuating refers to the ecosystem's ability to take control over the environment by fuelling the evolvement and development of learning niches within the ecosystem. Niche in ecology describes the habitat of the species and accompanying behavioral adaptation that allows the species to exist in that habitat. Hutchinson [36] defined niche as an abstract region (n-dimensional hyper volume) in a multi-dimensional space of environmental factors that affect the welfare of species. In smart, digitally enhanced learning ecosystems, the learning niche is a combination of certain ecosystem elements that people perceive and actualize as useful for their goal directed activities and well-being, individually or in group. Niches are supported and regulated by certain components. For example, "supporting Bring Your Own Device approach" is the learning niche that is regulated and promoted by Wi-Fi, school infrastructure, and innovative teaching practices, etc. Certain niches compete for the users' attention, e.g., schools tackle with two simultaneous goals-teaching digital competences as a lesson in computer class, and teaching digital competences as embedded in subject lessons using the BYOD approach. Hereby, we note that it is beyond the scope of this paper to define what the learning niches are in the learning ecosystems of the schools under the study. Instead, we focus how some of these learning niches are created and supported in the school ecosystem. In the smart, digitally enhanced learning ecosystem, human assets take control over the environment by participating in the niches' evolvements and developing them in line with their needs. They adapt and accommodate themselves to the niches in order to make the environment fit their needs and be sustainable.

Self-organizing ability accomplishes responsiveness of smart, digitally enhanced ecosystems. Self-organization in smart learning ecosystems is a bottom-up, participatory, and agent-driven process towards the sustainability of the ecosystem [37]. It provides the agents with self-realization opportunities. Such an ecosystem creates an environment where the agents' individual needs are met. Agents are kept in the state of positive tension where their skills are stimulated by adequate challenges.

\subsection{Efficiency of Smart, Digitally Enhanced Learning Ecosystems}

Energy efficiency describes the productivity of the ecosystem-efficiency with which the energy is transferred from one place to another, or transformed from one form to another. The higher the energy is preserved across the ecosystem, the more efficient or productive the ecosystem is. In natural ecosystems, most of the energy is lost at transformation phases. 
In smart, digitally enhanced learning ecosystems, the efficiency describes on one hand, how the digital mediating assets and the transforming services enable the digital learning, data, and information flows between the ecosystem assets, and how productively the ecosystem assets make use of it. Efficiency is also the quality depicting the flow of components among the human agents of the ecosystem: School leadership, teachers, and students, and their transformation on the individual and organizational levels.

\subsection{Smart, Digitally Enhanced Learning Ecosystems' States and Successive Developmental Stages}

After being ruptured, the digital learning ecosystems need to go through the developmental stages to sustain the efficient state. Digitally enhanced learning ecosystems' states can be described with different components, diverse interrelations among the components, and entropy level (or disorderness) on its different developmental stages [20]. A number of possible states and divergent developmental paths may be described in the digital learning ecosystems in the current time period of digital transformation of society. Some of them are directed to resource openness and build on the school stakeholders' pro-activeness, while others are top-down regulated and centrally provided with digital resources.

At the initial stage, after new digital innovations have been introduced to schools, the changes in input-output relationships cause instability, and the old system becomes disordered. As the new flows in the learning ecosystem increase, the internal organization is reorganized towards relatively lower entropy level, creating the necessary mediating assets, transforming services, and feedback loops. It requires high energy input. This stabilization process is constantly compromised by new ruptures caused by new innovations that are tested out in the school. These new innovations create learning niches. Several niches may be incrementally implemented in schools and may compete as well as disturb the existing mainstream system, until the system needs to invest too much energy to keep itself at low entropy level, such that radical changes have to be introduced [32].

Smart digital learning ecosystems are believed to accumulate more digital learning, data, and information flows because they use effective sensing mechanisms, create feedback loops from the flows to monitor and predict ecosystems' efficiency for self-reinforcement, and have the ability to actuate the external systems they are embedded into.

\subsection{Sustainability of Smart, Digitally Enhanced Learning Ecosystems}

The sustainability of smart, digitally enhanced learning ecosystems builds on the ecosystemic concepts explored above. The sustainability of smart learning ecosystems is dual: It may be seen as static notion-developmental state that meets the efficiency needs of the present day without compromising the future. The sensing and feedback loops, together with the self-organizing ability of the system, are the main ways in which system maintains the transformative stages to establish efficiently after being ruptured.

Secondly, sustainability may be seen as a dynamic notion of the system. It describes ecosystems' responsiveness to the possible future states, which may be created by sensing and making predictions to the possible futures, and by actuating internal and external changes. The big challenge is how to prompt educational systems to follow the dynamic notion of sustainability to mirror the digital transformation of society without compromising the educational solutions that have been in place for ages in schools. We posit that interactions between internal, and across internal and external components, of learning ecosystems and the external socio-technical landscape can indicate learning ecosystem sustainability-the potential of schools to sustain changes and their responsiveness to future states.

\section{Background on Georgian Case}

In this chapter, we introduce the context of our case study where we used the conceptual model of smart, digitally enhanced learning ecosystems for discovering the bottlenecks to sustainability. 
The educational decision-making process is centralized in Georgia [38]. Centralized, top-down vertical implementation is observed in generating digital polices and related changes on a school level [8]. The Ministry of Education and Science (MoES) of Georgia centrally equips school with computer technology, Internet, digital tools, and teacher training in technologies.

The school computerization program in Georgia began in 2005. Schools get computer technology on the basis of number of students. The average ratio of desktop computers reaches 30:1. Out of 2160 schools and educational resource-centers, 569 are provided with $100 \mathrm{mb} / \mathrm{s}$ optical Internet connection, the rest 1591 use radio-technology with $256 \mathrm{~kb} / \mathrm{s}-2 \mathrm{mb} / \mathrm{s}$. Computer technology is mainly located in computer labs. In some cases, schools have teacher notebooks and projectors for the use in classroom setting to present digital resources. Oftentimes, teachers prepare these resources in the form of PowerPoint presentations.

In 2011, Georgia started the ambitious program "Buki"-Netbooks for the first graders [8,20]. The Buki program was launched as the means to increase students' digital literacy. Since then, all the first graders and their teachers get netbooks on their first day of schooling as a present from the state. At the moment, all the students from 1st to 7th grade are equipped with bukis. Bukis operate with classroom management program that runs on the intranet network-the routers are installed locally in the classrooms. In most cases, there is no Wi-Fi access provided to the primary classroom where netbooks are used. The national curriculum imposes the ICT as a separate subject to be taught in the first semester of the 1st grade and also expects technology to be integrated in all subjects being taught in the primary education. Teachers who get Buki are obliged to take part in the yearly ICT training program over three years. There has not been any study that would measure the digital literacy of the students using Bukis or explore their utilization in the teaching and learning process.

MoES provides ICT training for the teachers. The training differs by the level of ICT complexity, as well as the methodology of ICT use, e.g., flipped classroom, ICT-enhanced project-based learning, etc. The training cycle is mandatory for primary school teachers holding the netbooks, while other teachers take it voluntarily. Training does not involve school leadership. In most cases, principals are unaware of the content of the training, or what kinds of skills the trained teachers have to use in the learning and teaching process.

MoES initiated the Teacher Professional Development and Advancement Scheme in 2015. Teachers collect the credits from different types of activities to be promoted in their teaching career. Among other activities, teachers can get the credits for the preparation of digital resources for the lesson, participation in distance learning course or ICT training/workshops for teachers, and keeping educational web-blog.

The national curriculum defines ICT as a separate subject to be taught in the 1st, 5th, and 6th grades. It is also interdisciplinary subject across all the disciplines in all grades. Schools can choose ICT as an elective subject. However, they often could not afford it because of the lack of competent human resources.

\section{Methods}

This paper is rooted in and informed by the case study where 15 schools of Georgia were qualitatively monitored. In the first phase of the study the schools were selected according to geographical location, school size, and digital learning activities. Interviews were recorded from 62 teachers, ICT managers, and school principals. Twenty-six lessons were observed to triangulate the findings from the interviews.

The qualitative data collection and analysis for the first phase was guided by the grid of digital services developed by us [39]. The grid of services unites 191 descriptors distributed within 3 education domains of digital infrastructure, learning facilitation, and change management; and 3 service groups of internal, external, and trade-off learning services [40]. Cluster analysis with data revealed 2 groups of schools: Digitally enhanced schools, and less innovative schools. Change management was identified as the biggest detriment between the school clusters [41]. 
For the present paper we used the findings from the first phase of the research and selected 2 participant schools from the digitally enhanced schools cluster. The schools were selected based on their activities (\#3 and \#9 schools from Table 1). Both schools have one computer lab where the digital devices are placed (12 computers and 22 computers, respectively). In addition, each school has 3 notebooks and 2 projectors that teachers can use in their classrooms. All students from the 1st to 7th grade are granted Bukis. In one of the schools, leadership was more focused to use technology as an administrative tool to implement changes, while another school leadership was more focused on promoting technology as a learning means. Teachers declared that they prepared digital resources on their own, and also let the students prepare digital products instead of being passive users of existing resources (e.g., teacher-led power point presentations, digital simulations, etc.). The purpose of using digital resources was mainly the introduction of information, topics, or concepts in a visual form to help students understand information better. Teachers declared they used more complex digital tools (as opposed to widely-spread utilization of power-point presentations) and also recognized the technical support from the leadership. The schools also described their participation in school-level technology-enhanced projects initiated from outside [41].

Table 1. Study participant schools in the 1st phase.

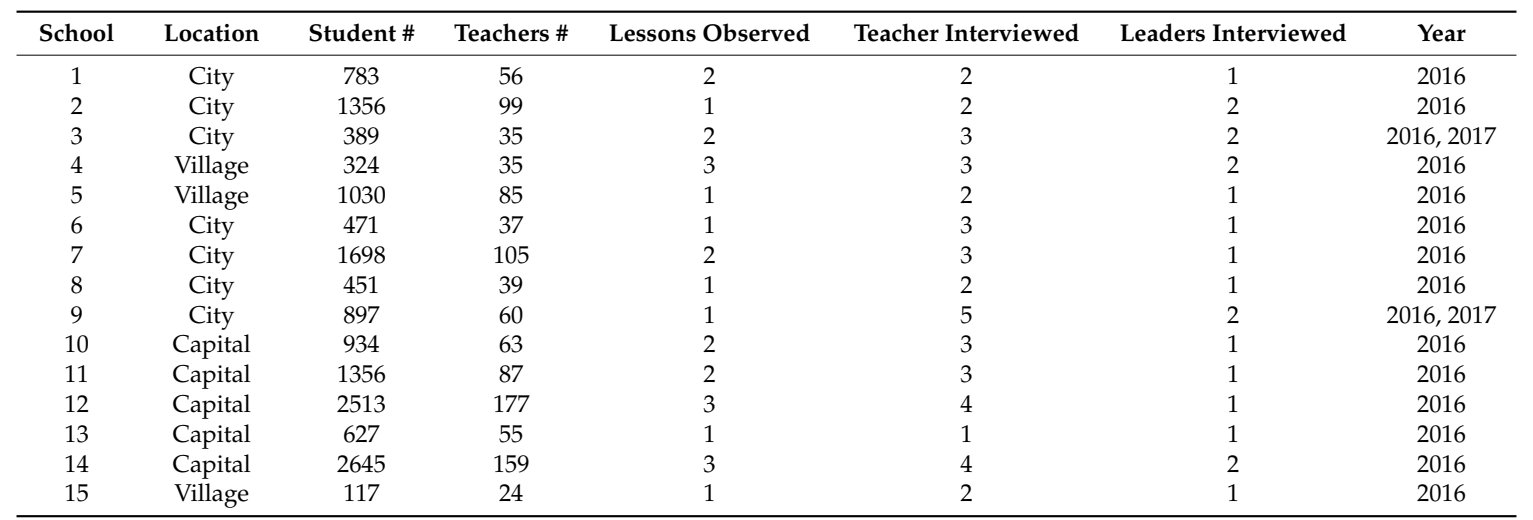

Note: All the schools include primary, secondary, and high school levels. In Georgia, all the educational levels are set together in the same building and have the same administration.

We recorded repetitive interviews from the selected 2 schools after 1 year to further explore digital change processes. We interviewed the same participants from the schools-2 principals, 2 ICT managers, and 8 teachers. In addition, interviews were recorded from 2 representatives from the Ministry of Education and Science of Georgia. Both sets of data from both years were used in this paper to answer the research questions.

We analyzed the qualitative data from 14 interviews (Table 2) using deductive content analysis. Krippendorp [42] defines content analysis as 'a research technique for making replicable and valid inferences from texts (or other meaningful matter) to the contexts of their use'. The outcome of the analysis is the categories that describe certain phenomena. Content analysis was accomplished in 3 phases: (a) Preparation phase that includes selection of the unit of analysis; (b) organizing phase that includes open coding, creating categories, and abstraction; and (c) reporting [43]. Deductive content analysis occurs when the structure of the analysis is based on the previous knowledge and the researcher aims to test existing concepts or hypothesis [44]. We followed deductive content analysis for our study because we aimed to test Georgian case against the conceptualized model of smart, digitally enhanced learning ecosystem. The data was coded using an unstructured matrix of the categories [43]. In the unstructured matrix, the researcher does not use pre-defined categories derived from the concept/theory that is under the study. On the contrary, the codes are emerging from the data using an inductive approach. 
The unit of analysis for this paper is 14 transcripts of recorded interviews. The analysis process was also informed with the information of the same schools and interviewees from the first phase of the research [41]. Anonymity of the participants is guaranteed. Therefore, to disclose their identity, we will use the letters SP (for school principal), SIM (for school ICT manager), ST (for school teacher), and NA (for national-level authorities). In the reporting, we use authentic citation to increase the trustworthiness of the research and describe where the data were taken from or what kind of data we used to form the categories [45].

Table 2. Demographics of the participants for the study in the 2nd phase.

\begin{tabular}{ccccc}
\hline Participant & Gender & Age & Experience in Years & Position \\
\hline 1 & Female & 44 & 4 & School Principle \\
2 & Female & 46 & 4 & School principal \\
3 & Female & 34 & 4 & Primary school teacher \\
4 & Female & 43 & 24 & Primary school teacher \\
5 & Female & 51 & 10 & Physics teacher \\
6 & Female & 43 & 20 & History teacher \\
7 & Male & 45 & 4 & ICT teacher \\
8 & Female & 42 & 14 & Georgian language teacher \\
9 & Female & 60 & 35 & Primary school teacher \\
10 & Female & 57 & 18 & Geography teacher \\
11 & Female & 41 & 12 & ICT manager \\
12 & Female & 43 & 16 & ICT manager, ICT teacher \\
13 & Female & 45 & 5 & National-level authority \\
14 & Male & 35 & 6 & National level authority \\
\hline
\end{tabular}

\section{Results}

We identified three categories in the data using the unstructured matrix of the deductive content analysis (Table 3): (a) "Adoptive responsiveness to external environment", which includes sub-categories of: External environment dictates digitally enhanced learning goals to the schools, event-orientedness, and implicit goals and ideas on a school level; (b) category "limited fitness of human agents' needs to learning niches" include sub-categories of: Learning niches designed by MoES requirements, and organizing and controlling mode; (c) "nonsufficient flow for the change" includes: One-way vertical communication for change, and different perspectives for success.

\subsection{Adoptive Responsiveness to External Environment}

Our study schools hold adoptive responsiveness to the external environment. Learning niches are formed by the requirements of external environment without active participation of the ecosystems' human agents in the process. Adoptive responsiveness limits ecosystems' capacities to activate transforming flows. In other words, schools take a passive stance to adjust or renew existing structures and processes to fit the requirements of wider socio-technical landscape.

The boundaries of external environment are rather limited and restricted to the Ministry of Education and Science of Georgia. The interviewees from all schools referred either to MoES and its agencies or the projects affiliated with MoES. Therefore, below we will use the term of external environment and MoES interchangeably. 
Table 3. Categories for smart, digitally enhanced learning ecosystems.

\begin{tabular}{|c|c|c|c|}
\hline & Sub-Category & Category & Summary of the State of Schools \\
\hline 5.1 .1 & $\begin{array}{l}\text { External environment } \\
\text { dictates the goals for the } \\
\text { digital activities. }\end{array}$ & \multirow{3}{*}{$\begin{array}{l}\text { Adoptive responsiveness } \\
\text { to external environment. }\end{array}$} & $\begin{array}{l}\text { Schools passively adopt the norms, rules, } \\
\text { and projects from MoES to enhance their } \\
\text { digital learning. }\end{array}$ \\
\hline 5.1 .2 & Event-orientedness & & $\begin{array}{l}\text { Schools passively respond to the scattered events } \\
\text { and processes coming from top-level, without } \\
\text { changing/adapting processes and structures on a } \\
\text { school level. }\end{array}$ \\
\hline 5.1 .3 & $\begin{array}{l}\text { Implicit goals and ideas } \\
\text { on a school level. }\end{array}$ & & $\begin{array}{l}\text { Members do not participate to design digitally } \\
\text { enhanced learning/vision to generate and } \\
\text { transfer new knowledge. }\end{array}$ \\
\hline 5.2 .1 & $\begin{array}{l}\text { Learning niches are } \\
\text { designed by MoES } \\
\text { requirements. }\end{array}$ & \multirow{2}{*}{$\begin{array}{l}\text { Limited fitness of human } \\
\text { agents' needs to } \\
\text { learning niches. }\end{array}$} & $\begin{array}{l}\text { Digital learning niches do not evolve based on } \\
\text { the members' needs within the ecosystem; they } \\
\text { are copied from and realized according to } \\
\text { MoES demands. }\end{array}$ \\
\hline 5.2 .2 & $\begin{array}{l}\text { Organizing and } \\
\text { controlling mode. }\end{array}$ & & $\begin{array}{l}\text { Communication process within the ecosystem is } \\
\text { based on control and administrative organization } \\
\text { of digitally enhanced activities, without clear } \\
\text { school-wide vision and goals. }\end{array}$ \\
\hline 5.3 .1 & $\begin{array}{l}\text { One-way vertical } \\
\text { communication } \\
\text { for change. }\end{array}$ & \multirow{2}{*}{$\begin{array}{l}\text { Nonsufficient flow for } \\
\text { the change. }\end{array}$} & $\begin{array}{l}\text { New experiences and generation of new } \\
\text { knowledge is strictly aligned with authoritative } \\
\text { top-down expertise. }\end{array}$ \\
\hline 5.3 .2 & $\begin{array}{l}\text { Different perspectives } \\
\text { for success. }\end{array}$ & & $\begin{array}{l}\text { Ecosystem agents interpret success indicators for } \\
\text { digitally enhanced learning in different ways. }\end{array}$ \\
\hline
\end{tabular}

\subsubsection{External Environment Dictates the Goals for Digitally Enhanced Activities}

Our study schools follow MoES requirements as the primary significance. Schools perceive themselves as part of the vertical implementation line, from the ministry and its supporting agencies to school principals and then classroom settings. School principals, ICT managers, and teachers repeatedly refer to different MoES requirements imposed on the school. Compliance with those requirements is the indicator to assess the appropriateness of initiated activities. Principals feel more persuasive in their decisions if they are associated with MoES requirements; they find it easier to involve teachers in the initiative.

We started shooting the video lessons. We made it mandatory ... I can't say there is something [worth] in it. This is requirement from the state. I try to begin before they [government officials] inspect [teachers] ... (SP). I raised their interest ... saying that this lesson or whatever you take from that training can be used later to realize "innovative lessons" [MoES project] (SP).

The external environment defines the focus of ICT integration and utilization in teaching and learning process. In other words, we can say that evolvement of learning niches is influenced by MoES requirements and less by individual needs. The e-tests seem to be the most implemented technology-enhanced activity within the schools. The MoES conducts Computer Adaptive tests (CAT). Eleventh and 12th graders have to pass the CAT in order to get their school graduation certificates. The school enforces the processes to meet the requirements. The ICT lab is used for e-test processing in different subjects while, due to the full schedule, it can be limited for other digital learning initiatives.

This room [ICT lab] is busy [with ICT lessons]. Only two days are free and we try to load it with e-tests (IM) ... Whether we like it or not we are doing a rehearsal for students [for CAT] (SP).

MoES regulations are the primary source for teachers' motivation to use technology for learning purposes. Teachers use technology as much as it meets requirements set by the Teacher Professional 
Development and Career Advancement Scheme. As a result, digital learning is used for the planned "demonstration lessons" where teachers demonstrate their technology skills to the colleagues. But the use of technology does not penetrate into the everyday classroom life.

Teachers' main motivation [to participate in ICT training] is the credit scores. Trainings have quite high credit scores ... So demand increased in that direction, however the use of technology in teaching and learning has not increased... Same teachers are active (NA). When we mention training [ICT training] teachers might kill each other in our school. It grows in the conflict who will go and attend ... But in reality 4-5 teachers work [with technology] mainly and the same faces always (SP).

\subsubsection{Event Orientedness}

In our study, we see that the course of actions conveyed to schools pushes them to be oriented at separate events. Study participants describe that MoES activities are scattered in separate events and lack consistency. Technology is not part of "real" teaching and learning process. National ICT curriculum content, for example, is defined based on what competencies and skills school actors have at the moment.

If you tell math teacher first teach excel sheets and then apply it as a tool, you go to the point that this person does not know excel well. You prefer to bring non-mathematician, the person who knows excel, and he demonstrates the tool with specific cases, then math teacher goes to the lesson and applies it [skills]. This is the idea but [in reality] problem is the person [math teacher] does not use it [student ICT skills]. As a result, students do not know the tool the other day, because it was not functional application of the tool. It was shown like "click here", "it opened", "now draw the diagram" ... he [student] got knowledge but no one converted it into the skills (NA).

Buki implementation is one of the examples how the external requirements are implemented on a school level. For school actors, the project lacks consistency and systemic thinking. Schools do not have mechanisms for using technology to enhance pedagogy. Teachers neglect Bukis in most cases because of the lack of technical and methodological support inside and outside the school.

Lack of long-term vision pushes schools to be dictated by the symptomatic solution of challenges instead of looking for fundamental changes. They are oriented to short-term solutions vs. long-term ideas and goals on the school level.

Whatever is mandatory we are really doing, everyone does despite the age (ST). Scheme activated the teachers. They saw they had to upload lesson plans and resources (IM).

Questions and ambiguity exist towards the national ICT curriculum. The curriculum defines ICT as a separate subject as well as transversal subject integrated in different teaching disciplines. However, for the participants of this study, it is not clear and can be interpreted in different ways. All participants, including national authorities, school principals, and teachers, highlighted the importance of clearer instructions.

Curriculum should set requirements... If you do not set requirements, only some enthusiastic teachers will do something. If someone uses technology she/he is a volunteer, no one asked for it ... (NA). It [ICT] stayed as a separate subject in the 1st grade [in a revised curriculum] ... Bukis are tied to ICT subject ... and in fact students use only for ICT subject. And [subject] teachers do not consider that it [buki integration] is their job too ... the bukis go to shelf second year ... Somehow the whole concept is ruined (NA).

\subsubsection{Implicit Goals and Ideas on a School Level}

The schools from digitally enhanced cluster have a digital agenda and it is one of the major variances between the two groups. However, the goals are either oriented at using technology as an 
administrative tool or they are implicitly described. It leads to technology being considered as an add-on to the teaching process, not the integral part of teaching and learning.

Create and develop ICT system ... create school website, create e-copies, and archive all school-relevant information; organize school data in electronic format [the extract from school strategy] ... So what I have about ICT ... it is not included ... to use ICT for innovative practices to get high quality results (SP).

Qualitative analysis of the data shows that these agendas are solely formed by principals, and not even communicated properly with the school community. Lack of communication on the school vision causes teachers to remain unaware of their mental models; models remain unexamined, and unchanged. Meanwhile, the environment changes and the gap widens.

It [strategy] is introduced on the teachers meeting... I could not say they know it by heart ... No one [speaking about other schools' experiences] reads strategy at the teacher meeting; sometimes it is approved without introducing [to the teachers] (SP).

\subsection{Limited Fitness of Human Agents to Learning Niches}

Learning niches evolve based on the requirements of the external environment. Thus, it limits the capacity of human agents to actively participate in the creation of learning niches and therefore the learning niches to be fit to agents' actual needs. Hereby, we note that it is beyond the scope of this paper to analyze what the needs of human agents are. We instead focus on how these needs are considered in implementation of innovative practices, focusing on teachers as human agents of the ecosystem.

\subsubsection{Learning Niches are Designed to MoES Requirements}

Processes at schools are directed to fulfill MoES requirements while limiting the consistent structures at place to support individual needs. As a result, digital learning niches do not evolve and they remain unrecognized/unidentified by the agents in the ecosystem.

Students do presentations at home and then present in the classroom to their friends ... Sometimes

Students bring presentations on flash drives and I could not open it at the lesson [because of lack of technology and access to computer lab] (ST).

Schools do not support the Bring Your Own Device approach, despite the teacher and student needs and their motivation to use technology. Surprisingly, teachers do not look at it as an opportunity for their classroom.

\subsubsection{Organizing and Controlling Mode}

In our study, the school principals distinctly control processes, with ICT managers supporting in technological challenges.

The whole communication process from teachers to principal is straightforward and linear, a one-way controlling mode. Teachers collect and send information to the principal or ICT manager. The principal checks its compliance to the prescribed norms. Information is discussed back if it has some inconsistency with the rules. There's no space for teachers to discuss digital learning challenges and practices, in the best cases they get only the technical support from ICT manager. One participant teacher described how she abandoned digital learning activities because she did not feel confident or supported by the environment. Meanwhile, the same teacher referred to having the principal's support in other teaching challenges. In many cases, teachers are not aware whom to address to discuss digital learning issues. The main reason for supporting technology use from the leadership is establishing monitoring and control mechanism.

Last year I was new and I was lost in so much documentation, monitoring was very difficult ...

Now control is very easy [she implemented use of Google Drive across school for administrative purposes]. 


\subsection{Nonsufficient Flow for the Change}

In our study, we see principals impose separate activities without engaging school actors and having even different perspectives for digital learning integration success indicator. It does not equip the principals with a strong leverage system for the systemic integration of technology in the teaching and learning process.

\subsubsection{One-Way Vertical Communication for Change}

The actions defined on the top-central level are the main driver of the processes in our schools of study. School principals point to the cultural phenomenon and explain the difficulties to activate the processes.

Unfortunately, our society is used that if the task is not coming from the top, it is not accomplished; it won't be done in an appropriate quality (SP). As it usually happens, at the beginning no one [teachers] wants to change anything, when the requirements come [from MoES] then the will [to change] comes too (SP).

The same line continues on a school level. In most cases, teachers follow principal or ICT manager instructions for the change without taking responsibility for their own actions. School leaders take decisions without the direct involvement of the rest of school community.

If I assign the task it will be done, I do not like it ... They are used to do whatever they are told to do.

They are afraid that their actions might be inadmissible (SP).

When teachers are talking about sharing digital learning practices, they refer to ICT trainer from MoES centralized trainings, ICT manager at school, or school facilitators for subject groups who are usually the people with advanced ICT skills. They are looking for the new experience from someone superior to them. Information sharing is always one-way, getting specific information/knowledge or resources from the technology-advanced person at a specific time of need.

Information manager gives us the news and when we try to use and implement the innovation (ST).

I periodically offer training to introduce new tool and teach how to work in the tool (IM).

School-initiated innovative practices lack consistency and support to the agents. The process of planning and implementation is not structured or aimed at supporting teachers; rather, it is giving the instruction what to do.

Last year I suggested to some teachers, who can do such things ... suggested the lessons [to prepare the lessons] for distance learning. It should be something for $15 \mathrm{~min}$... I suggested at the end of the last year... I thought they will start working from the first semester, but they said it appeared to be difficult ... I will remind them next semester (SP).

\subsubsection{Different Perspectives for Success}

Interestingly, different agents-school principals, ICT managers, and teachers-use different indicators while describing the progress in their practice after one year. For school principals, these indicators are the number of teachers using the computer lab; for the ICT manager-the number of teachers asking for help; while teachers mostly focus on the improvement of the quality of digital resources, and moving from teacher-produced to student-produced resources.

\section{Discussion}

In this paper, we hypothesized the model of smart, digitally enhanced learning ecosystems based on the ecosystem metaphors. We defined responsiveness and efficiency as quality attributes for the smartness of the digitally enhanced learning environment. We will analyze the bottlenecks that 
impede schools' sustainable development into smart, digitally enhanced learning ecosystems based on the data from Georgian schools (Figure 2) and discuss our suggestions how these bottlenecks could be overcome.

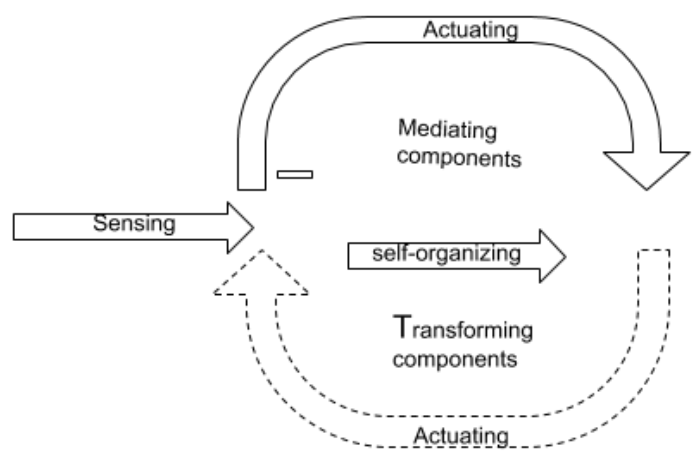

Figure 2. Digitally enhanced learning ecosystem's operation in Georgia. The "-" symbol indicates the lack of self-reinforcement processes that results in diminishing actuating processes.

In our participant schools, we see that ecosystems receive the signal of the external environment. For illustration we refer to e-test integration in the learning process. The schools notice the signal from MoES — sensing ability—to implement the digital activity. Despite the controversial opinions of the actors on the benefit of e-tests in their learning process, the ecosystem begins to actuate its mediating and transformative components to accommodate the need of the external environment. Computer labs are used mainly for the ICT lessons to comply with the requirements of national curriculum and e-tests to prepare students for MoES CAT exams. Teachers who prepare digital resources and learning scenarios to integrate technology in the subject teaching have problems with accessing school technology. Schools do not promote the 'bring your own device' approach and neither have clear idea how to use Bukis. We can see that schools are inclined to use limited resources to respond to the MoES requirements instead of the evolving needs of the human actors there. We can conclude that certain limiting factors influences the sensing capabilities of the ecosystem in terms of responding to the signals: The limited scope of the external environment pushes the school to be directed only to one sender's signal and hinders its capability to diversify the needs in the broader socio-technical landscape. Another impediment is the lack of self-reflection from the actors on their individual needs. Argyris [15] encourages self-reflection and development of mental models [14] that question the goals and decision-making rules. In double-loop learning, actors identify the ways in which they can contribute to the organization and change behavior accordingly.

Obviously there are no processes at school that would engage teachers in mutual conversation, self-reflection, and development of mental models. Vertical line of implementation and lack of participation in the processes results in implicit goals on the school level. The teachers and ICT managers do not know the schools' digital agendas and the goals they want to accomplish with digital learning. All respondents (teachers, principals, and ICT managers) describe a straightforward and linear communication process that is based on control from higher to lower hierarchical position, or specific technical support how to use a certain digital tool. We believe that in smart, digitally enhanced learning ecosystems the signals from external environment causes cognitive dissonance in the human actors, the actors notice the ruptured situations in the environment (sensing) and begin actuating the means (transformative components) to make use of themselves and of available tools in the ecosystem. Indicators of ruptured situations can be: Noticed difference between old and new knowledge and competences in self, or noticed difference of knowledge and competences between self and the group [46]. Both self-reflecting individually in problem situations and learning in social settings provide conditions for the ruptured situations and self-directed actions. Gillespie [46] discusses theories of self-reflection in ruptured situations, in which actors have more than one response 
to the situation that needs decision-making, and thus self-reflection on the arguments is induced; furthermore, in groups and communities where actors reflect upon the rules and conditions of the ongoing interaction that leads to the personal self-reflection. Conversations with others or with self (by explicit process monitoring) enable us to clearly formulate our responses to the ruptured situations and make our thinking clearer to us.

In our sample, we see that schools actuate their already existing mediating and transformative components: Tools, resources, processes, rules, and support mechanisms. Though there are not clear signs of looking for new mediating components or creating the transformative components that would contribute to forming learning niches and accompanying digital learning flows in the ecosystem. The schools under the study in this paper have digital agendas distinctive to other schools from the first phase research. Though the agenda mainly looks at the technical aspect of the technology use and does not include development or implementation of the transformative components (support, rules and regulations, etc.).

In our hypothesized smart, digitally enhanced learning ecosystem, we expect the digital innovations (or signals) will bring instability and change the relationship of the constituent components of the ecosystem. Learning niches would evolve that bring new flows in the ecosystem until the new system is internally reorganized and stabilized. The impediments that we see in our sample are as follows: The nature of innovation itself tries to preserve the status-quo in the ecosystem. The status-quo state is preserved from the external environment-as we see it present for our ecosystems. As an example, we can bring the explanation of our respondent expert on how the national ICT curriculum was formed. The curriculum was formed to comply with the existing digital competences of the teachers, even though those competencies were assessed as low. On the other hand, MoES launched Buki program to support digital literacy in primary education. The Buki program has been going on for seven years now. Schools follow defensive routines [15] to blame external forces for the gaps in the program: Supporting policies, programs, or even technical service for buki. Schools preserve the status-quo state with their already-existing rules, teaching and learning processes, and support mechanisms, without experimenting new ways with Bukis and supporting the learning niches to evolve [15]. Another impediment is the passive participation of ecosystems' human actors in the processes that result in preserving the status-quo. In other words, schools lack the ability to self-organize itself to meet the requirement of the present day and wider socio-technical landscape. School leaders and teachers are passive recipients of the signals.

Therefore, in our sample schools we see the cycle of sensing, actuating, and organizing activities. However, this cycle does not support reinforcement processes in the ecosystem. Certain conditions are necessary to nourish the responsive and dynamically sustainable nature of the learning ecosystems. First, broader scope of external environment will help the schools to gain and accumulate new knowledge connected to digital learning. It will support schools to develop sensing ability to signal and adapt to the requirements of socio-technical landscape. Burns and Köster [47] defined the potential stakeholders in education: Training and educational material providers, private business, parents and communities, local authorities, school boards and school providers, Ministry and government agencies, NGOs and labor unions, media, researchers, and international organizations. Kools and Stoll [3] highlight the importance of open systems because they have more ability to learn and to discover and embrace changes.

Second, human agents' involvement in ecosystem development will provide them with self-organization opportunities, and support schools to be responsive to their needs. Schools will enhance their capacity to promote the interaction of human agents with ecosystem components and encourage evolution of learning niches. Heifetz and Linsky [48] use the term "adaptive" to describe twenty-first century educational challenges. These are the challenges that cannot be solved by authoritative expertise or usual operating procedures, because they require experiments, new discoveries, and adjustments from numerous places in the organization or community. We describe our schools with the term adoptive versus adaptive. The schools under the study lack the support to 
learn the new ways and empower people to make the adaptive leap necessary to thrive in the new environment. While talking about the control over the environment, we do not consider centralized versus decentralized system as the proper discourse of discussion. Effective governance is a set of strategic visions, set of processes, and stakeholder involvement that can be achieved in both centralized and decentralized systems [9]. The role of central governance is providing system-wide vision, developing clear guidelines and goals, or providing feedback on the progress of goals [9]. We see the challenge of closed system not as much in a vertical implementation itself but mostly in a lack of bottom-up initiatives to align with top-down activities. Presence and multiplicity of bottom-up strategies, whether centralized or decentralized, shows the ownership from the lower levels of the ecosystem and therefore indicates the success for the change [8].

Third, granting the schools with self-organization opportunities will trigger the self-reinforcement processes. In the Georgian case, we see that the activities have one-way flow from one level to another, rather than circular movement (Figure 2). Schools are oriented on separate events and symptomatic solutions as a result of non-circular feedback loops. They implement these events without fundamental long-term design addressing the challenges from the wider socio-technical landscape. In smart, digitally enhanced learning ecosystems, digital learning flows inform the mediating and transforming components to support self-reinforcement process in the ecosystem (Figure 1). Schools use the data analytics and information to meet the individuals' need on one hand, and use the data to predict the future state on the other hand. This challenge was especially clear in Georgian schools during the repetitive interviews from the same participants after one year. Some teachers highlighted that they diminished the use of technology; others kept on using it in the same way. On a school level nothing was changed, as principals reflected.

Fourth, the self-reinforcement processes in the ecosystem entail better energy transfer among components and human agents, that results in efficient operation of the ecosystem as a whole (Figure 1). Though, self-reinforcement processes bring instability and entropy to the ecosystem. Therefore, supporting the schools to develop resilience to ruptured situations and quickly react to them are important skills for the schools to gain.

In our conceptualized model, we defined sustainability as central criteria for the smartness of digitally enhanced learning ecosystem. Sustainability can be achieved through the sensing, self-organizing, and self-reinforcement abilities of the ecosystem. In other words, these abilities are important attributes to sustain efficiency in the current state of the ecosystem after being ruptured by the innovations - the static sustainability. On the other hand, responsiveness to the socio-technical landscape defines the dynamic sustainability of the ecosystem, in other words its ability to predict and be responsive to the future states of the system. We listed certain factors and conditions that limit school responsiveness (sensing, actuating, and self-organization). The same factors and conditions constrained learning ecosystems' efficiency to accumulate more digital learning, data, and information flow that are important indicators of smart, digitally enhanced learning ecosystems. The limitation in learning ecosystems' sensing, actuating, and self-reinforcement abilities are the bottlenecks that constrain the sustainability of smart, digitally enhanced learning ecosystems and therefore needs to be addressed.

Based on the results of the paper, we suggest schools develop the smart and dynamically sustainable digitally enhanced learning ecosystem by: Building on the inclusive involvement of different stakeholders in digital transformation; nourishing their resilience to ruptured situations appearing from external and internal innovation processes; widening the development, testing, and up-taking of digitally enhanced learning activities that open up schools to the communities; weaving internal networks for sharing new practices; conducting outreach activities which contribute to the change in external socio-technical landscape; and developing feedback loops from learning, data, and information flows to manage changes.

We acknowledge that the study has certain limitations. We observed the schools under the study over three years, which gives us the confidence to make conclusions on the development of learning 
ecosystem there. However, we acknowledge that the sample size is not sufficient. Further studies are important to test our hypothesized model of the smart, digitally enhanced learning environment and the schools fit to the model.

We acknowledge that cultural phenomena are an important aspect to consider. So the insights from different cultural backgrounds will further enhance the findings of our study. In this study we included the schools from different regions of Georgia to observe the general trends.

We consider that the data from students is an important asset to further develop our research. Especially on the topic of the digital learning flows of the ecosystem. However, in this paper we focus on the organizational level factors and do not explore the digital learning activities of the schools. In the next stage of the research, when we explore deeper the digital learning flows and their nature, we will need more data from the students.

For the future work we designed the training course for the school representatives based on the findings of this paper. The training will be held for the study participant schools. After the intervention study we will further explore how the change in these components will influence schools' transformation to smart, digitally enhanced learning ecosystems.

\section{Conclusions}

In this paper, we hypothesized the smart, digitally enhanced learning ecosystem and explored the measures of the smartness and sustainability. To our understanding, smart, digitally enhanced learning ecosystems dynamically evolve with participation of the human agents of the ecosystem and continuously change with and in relation to the internal and external environments. The system self-reinforces itself by allowing evolvement and development of learning niches, which complies with the requirements of the external environment and at the same time responds to the individual agents' needs. We suggest the following directions as important assets to develop smart, digitally enhanced learning environments: Involve different stakeholders in digital transformation, develop schools' resilience to ruptured situations, broaden digitally enhanced learning activities, develop networking capabilities inside and outside the school, and use the digital data and learning to manage changes.

We can summarize the bottlenecks to sustainability in Georgian case as follows: The closed system of the schools and passive participation in school-wide operations limit schools' capacities to build smart, digitally enhanced learning environments. Activities and innovative practices are dictated from the external environment. The external environment itself is rather limited in scope and does not encourage modification of the internal structures in the schools. Schools do not have explicit visions for change and follow short-term processes that are initiated by the external environment. Event-focused structure leads to reactive behavior to external requirements, thus putting the focus on symptomatic solution, not long-term vision for fundamental changes.

We assume the findings will be interesting for the policy makers in Georgia to design and implement technology-related projects and programs for schools. In addition, the findings will assist the researchers who are working on the issues of technology integration on the school level.

Author Contributions: E.J. collected the data, transcribed, and analyzed. Both authors took part to design the conceptual model of smart, digitally enhanced learning environments, to map the results to the conceptualized model, and to write the article.

Funding: This research received no external funding.

Conflicts of Interest: Authors declare no conflict interest.

\section{References}

1. European Commission. Digital Agenda for Europe-Rebooting Europe's Economy; European Commission: Brussels, Belgium, 2014; pp. 1-8. [CrossRef]

2. Kampylis, P.; Punie, Y.; Devine, J. Promoting Effective Digital-Age Learning-A European Framework for Digitally-Competent Educational Organisations; Joint Research Centre: Belgirate, Italy, 2015. 
3. Kools, M.; Stoll, L. What makes a school a learning organisation? In OECD Education Working Papers; OECD Publishing: Paris, France, 2016; Volume 137, pp. 1-89.

4. Underwood, J.; Dillon, G. Chasing dreams and recognising realities: Teachers responses to ICT. Technol. Pedagogy Educ. 2011, 20, 317-330. [CrossRef]

5. Broadbent, S.; Cara, F. Seeking control in a precarious environment: Sustainable practices as an adaptive strategy to living under uncertainty. Sustainability 2018, 10, 1320. [CrossRef]

6. OECD. OECD innovation strategy 2015. An agenda for policy action. In OECD Reviews of Innovation Policy; OECD Publishing: Paris, France, 2015; pp. 395-423. [CrossRef]

7. Davis, N.; Eickelmann, B.; Zaka, P. Restructuring of educational systems in the digital age from a co-evolutionary perspective. J. Comput. Assist. Learn. 2013, 29, 438-450. [CrossRef]

8. Kampylis, P.; Law, N.; Punie, Y. ICT-enabled innovation for learning in Europe and Asia. In Exploring Conditions for Sustainability, Scalability and Impact at System Level; Publications Office of the European Union: Luxembourg, 2013.

9. OECD Centre for Educational Research and Innovation. Schools at the Crossroads of Innovation in Cities and Regions; OECD Publishing: Paris, France, 2017. [CrossRef]

10. Davis, N.E. How may teacher learning be promoted for educational renewal with IT? In International Handbook of Information Technology; Voogt, J., Knezek, G., Eds.; Springer: Boston, MA, USA, 2008.

11. Fullan, M. Choosing the Wrong Drivers for Whole System Reform; Centre for Strategic Education Seminar Series Paper No. 204; Centre for Strategic Education: Melbourne, Australia, 2011. Available online: http: / / www.cse.edu.au/Publication.aspx?p=398 (accessed on 10 July 2011).

12. Hargreaves, A.; Fullan, M. Professional Capital: Transforming Teaching in Every School; Routledge: London, UK, 2012.

13. Istance, D. Schooling Redesigned: Towards Innovative Learning Systems; OECD Publishing: Paris, France, 2015.

14. Senge, P.M. The fifth discipline, the art and practice of the learning organization. Perform. Instr. 1991, $30,37$. [CrossRef]

15. Argyris, C. Double loop learning in organizations. Harv. Bus. Rev. 1977, 55, 115-125.

16. Underwood, J.; Dillon, G. Capturing complexity through maturity modelling. Technol. Pedagogy Educ. 2004, 13, 213-225. [CrossRef]

17. Hamel, G.; Valikangas, L. The quest for resilience. Harv. Bus. Rev. 2003, 81, 52-63. [PubMed]

18. Stetsenko, A. From relational ontology to transformative activist stance on development and learning: Expanding Vygotsky's (CHAT) project. Cult. Stud. Sci. Educ. 2008, 3, 471-491. [CrossRef]

19. Zhao, Y.; Frank, K.A. Factors affecting technology uses in schools: An ecological perspective. Am. Educ. Res. J. 2003, 40, 807-840. [CrossRef]

20. Jeladze, E.; Pata, K.; Quaicoe, J. Factors determining digital learning ecosystem smartness in schools. Interact. Des. Archit. 2018, 35, 1-21.

21. Di Fabio, A. The psychology of sustainability and sustainable development for well-being in organizations. Front. Psychol. 2017, 8, 1534. [CrossRef] [PubMed]

22. Lewin, C.; Scrimshaw, P.; Somekh, B. The impact of formal and informal professional development opportunities on primary teachers' adoption of interactive whiteboards. Technol. Pedagogy Educ. 2009, 18, 173-185. [CrossRef]

23. Hattie, J. Visible Learning: A Synthesis of over 80 Meta-Analyses Relating to Achievement; Routledge: London, UK, 2009.

24. Järvilehto, T. The theory of the organism-environment system: I. Description of the theory. Integrat. Physiol. Behav. Sci. 1998, 33, 321-334. [CrossRef]

25. Albrechtsen, H.; Andersen, H.H.; Bødker, S.; Pejtersen, A.M. Affordances in activity theory and cognitive systems engineering. In Rapport Technique Riso; Riso National Laboratory: Roskilde, Denmark, 2001.

26. Marshall, S. A quality framework for continuous improvement of e-learning: The e-learning maturity model. J. Distance Educ. 2010, 24, 143-166.

27. Vanderlinde, R.; van Braak, J. A new ICT curriculum for primary education in Flanders: Defining and predicting teachers' perceptions of innovation attributes. Educ. Technol. Soc. 2011, 14, 124-135.

28. SELFIE Tool. Available online: https:/ / selfie.jrc.es/ (accessed on 25 May 2018).

29. DigitalMirror. Available online: https://www.slideshare.net/martlaa/digital-mirror-measuring-the-digitalinnovation-maturity-in-estonian-schools (accessed on 25 May 2018). 
30. Reyna, J. Digital teaching and learning ecosystem (DTLE): A theoretical approach for online learning environments. In Proceedings of the ASCILITE-Australian Society for Computers in Learning in Tertiary Education, Hobart Tasmania, Australia, 4-7 December 2011; pp. 1083-1088.

31. Frielick, S. Beyond constructivism: An ecological approach to e-learning. In Proceedings of the 21st ASCILITE Conference, Perth, Australia, 5-8 December 2004; pp. 328-332.

32. Geels, F.W. Technological transitions as evolutionary reconfiguration processes: A multi-level perspective and a case-study. Res. Policy 2002, 31, 1257-1274. [CrossRef]

33. Bray, D.A.; Konsynski, B.; Thomas, D. IS-Driven Organisational Responsiveness; Emory University: Atlanta, GA, USA, 2007. Available online: http:/ / papers.ssrn.com/sol3/papers.cfm?abstract_id=984598 (accessed on 25 May 2018).

34. Jacobs, C. Managing Organisational Responsiveness—Toward a Theory of Responsive Practice; DUV: Wiesbaden, Germany, 2003.

35. Daft, R.L.; Weick, K.E. Toward a Model of Organizations as Interpretation Systems. Acad. Manag. Rev. 1984, 9, 284-295. [CrossRef]

36. Hutchinson, G.E. Population studies: Animal ecology and demography. Bull. Math. Biol. 1991, 53, $93-213$. [CrossRef]

37. Giovannella, C.; Andone, D.; Dascalu, M.; Popescu, E.; Rehm, M.; Roccasalva, G. Smartness of learning ecosystems and its bottom-up emergence in six European Campuses. In Smart Learning Ecosystems in Smart Regions and Cities; EC-TEL 2015; Aalborg University: Aalborg, Denmark, 2015; pp. 1-12. Available online: http:/ / www.researchgate.net/publication/280720970 (accessed on 25 May 2018).

38. Gorgodze, S. Rise and fall of decentralized school governance-Decision-making practices in Georgia. Int. Educ. Stud. 2016, 9, 25. [CrossRef]

39. Digital Learning Ecosystem Grid. Available online: https://www.researchgate.net/publication/323309836_ Digital_Learning_Ecosystem_Grid (accessed on 25 May 2018).

40. Jeladze, E.; Pata, K. Technology investment and transformation efforts in the public schools of Georgia. In Lecture Notes in Computer Science (Including Subseries Lecture Notes in Artificial Intelligence and Lecture Notes in Bioinformatics); Springer: Berlin, Germany, 2016; Volume 10013, pp. 60-71.

41. Jeladze, E.; Pata, K. Change management: Digital transition in the public schools of Georgia. Commun. Comput. Inf. Sci. 2017, 734, 171-184. [CrossRef]

42. Krippendorp, K. Content Analysis: An Introduction to its Methodology; Sage: Thousand Oaks, CA, USA, 2004.

43. Elo, S.; Kyngäs, H. The qualitative content analysis process. J. Adv. Nurs. 2008, 62, 107-115. [CrossRef] [PubMed]

44. Lauri, S.; Kyngäs, H. Developing Nursing Theories (Finnish: Hoitotieteen Teorian Kehittäminen); Werner Söderström: Helsinki, Finland; Dark Oy: Vantaa, Finland, 2005.

45. Patton, M.Q. Qualitative Evaluation and Research Methods; Sage Publications: Newbury Park, CA, USA, 1990.

46. Gillespie, A. Social basis of self-reflection. In Cambridge Handbook of Sociocultural Psychology; Jaan, V., Alberto, R., Eds.; Cambridge University Press: Cambridge, UK, 2007; pp. 678-691.

47. Burns, T.; Köster, F. Governing education in a complex world. In Educational Research and Innovation; OECD Publishing: Paris, France, 2016.

48. Linsky, M.; Heifetz, R.A. Leadership on the Line: Staying Alive through the Dangers of Leading; Harvard Business School Press: Cambridge, UK, 2002; ISBN 1578514371.

(C) 2018 by the authors. Licensee MDPI, Basel, Switzerland. This article is an open access article distributed under the terms and conditions of the Creative Commons Attribution (CC BY) license (http://creativecommons.org/licenses/by/4.0/). 